\title{
Stereochemical engineering of a peptide macrocycle allosteric inhibitor of phospho-Akt2 controls cell penetration by fine-tuning macrocycle-cell membrane interactions
}

Arundhati Nag, ${ }^{\text {b d }}$ Amirhossein Mafi, ${ }^{b}$ a Samir Das, ${ }^{b}$ Mary Beth Yu, ${ }^{b}$ Belen Alvarez-Villalonga, ${ }^{b}$ William A. Goddard III, ${ }^{b, a}$ and James R. Heath* b,

a Materials and Process Simulation Center (139-74)

${ }^{\mathrm{b}}$ California Institute of Technology, Pasadena, California 91125, United States

${ }^{\mathrm{c}}$ Institute for Systems Biology, Seattle WA

${ }^{d}$ Clark University, Worcester MA 01610

Arundhati Nag: Email: anag@clarku.edu ; ORCID: 0000-0002-1328-1695

Amirhossein Mafi: Email:amafi@caltech.edu ORCID: 0000-0002-8366-6785

Samir Das: Email: samdas@clarku.edu

William A. Goddard III: E-mail: wag@caltech.edu; ORCID:0000-0003-0097-5716

James R. Heath: Email: jheath@systemsbiology.org ORCID: 0000-0001-5356-4385

\section{Abstract:}

We report the development of a cell-penetrant cyclic loop biligand that selectively binds, in vitro, to the phosphorylated Ser474 site of Protein Kinase B (p-Akt2) with high affinity $\left(K_{D}=10 \mathrm{nM}\right)$. The cyclic loop biligand consists of a linear peptide joined to a macrocycle peptide through triazole linkage, and it was isolated through two iterative in situ screens. This biligand allosterically inhibited kinase activity of Akt2 but it was cell-impermeable, as isolated from the screening process. Since Akt2 is an oncoprotein hyperactivated via phosphorylation at Ser474 in cancers, we sought to visualize p-Akt2 in live cancer cells using the developed biligand. To this end, we matured this biligand into a cell-penetrant reagent through systematic iterations of its chemical structure to promote cell-penetrating properties, while retaining its binding and inhibition for $\mathrm{p}$ Akt2. Two retro-inverso, N-methylated versions of the macrocyclic ligand were developed which were uptaken by live cancer cells, while retaining their high affinities for pAkt 2 . Interestingly, the stereochemistry of two amino acid residues in the cell-penetrant ligands exhibited strong influence on their extent of cell penetration. This phenomenon of difference in cell penetration was explored through metadynamics simulations of each ligand in the cell membrane. It was found that the ligand uptaken to a greater extent by cells had more intramolecular interactions with itself and had fewer cholesterol molecules associated with it, which aided in its cell-penetration.

\section{Introduction}

Phospho-kinase signaling provides the central method of regulating trans-membrane and intracellular signal transduction pathways ${ }^{1}$. Genetically encoded hyper-activation of such pathways within many cancer cell types is reflected in elevated levels of phosphorylation of the individual protein kinase pathway elements, relative to that seen in healthy cells ${ }^{2}$, and those protein 
kinases can serve as important drug targets ${ }^{3}$. In addition, antibody staining of fixed tumor tissues for specific phosphorylated protein epitopes can provide a tool for identifying cancer cells and defining tumor margins ${ }^{4}$. Carrying out such imaging in live cells or tissues, while desirable, is not practical because phospho-specific antibodies are not cell-penetrant ${ }^{5}$. An alternative to antibodies for live cell imaging of phospho-proteins are macrocyclic peptide ligands ${ }^{6}$. However, while some naturally occurring peptide macrocycles are cell-penetrant ${ }^{7}$, most are not. Synthetic toolkits for optimizing cyclic peptides for cell penetration ${ }^{8}$ have been reported, ${ }^{9}$ but, for a targeted macrocycle, such modifications need to be balanced with the need to retain its target-specific (i.e. binding and inhibition) characteristics ${ }^{10}$. This can be a severe limitation. Consequently, cell penetrating peptide sequences (CPPs) are often appended to targeted moieties to promote cell penetration. ${ }^{11}$.

A tool which might be applicable for tuning cell penetration of cyclic peptides is that of stereochemistry. N-methylation of cyclic peptides is a stereochemistry tuning tool that makes peptide bonds rigid, thus increasing the cell-penetration capabilities of non-polar cyclic peptides ${ }^{12}$. Other approaches such as retro-inversion can maintain the overall structure of the cyclic or linear peptide, while inverting both the direction of the peptide sequence and the chirality of the amino acids $^{13}$. Certain retro-inverted cyclic analogues of the cyclic enkephalin peptide showed significantly increased protease stability and biological activity ${ }^{14}$, while cyclic retro-inverted analogs of somastatin have shown decrease in potency but significant in vivo activity ${ }^{15}$. Retroinversion of a macrocyclic peptide, therefore, may or may not help in increasing its biological activity, even if it increases protease stability. In In this article, we report the development of a cell-penetrating phosphoAkt specific peptide macrocycle by combining selective N-methylation, retro-inversion and systematic stereochemical modification of side chains of certain amino acids. We converted a cell-impermeable macrocyclic peptide into its cell penetrating analog through a combination of retro-inversion, $\mathrm{N}$-methylation and systematic modification of the stereochemistry of certain amino acids, focusing on retaining high affinity of the macrocyclic ligand for the phosphorylated active Akt2 protein as a guiding principle. Our approach permitted the retention of both pAkt binding and kinase inhibition. We previously developed an all-synthetic technology, Chemical Epitope Targeting (CET) ${ }^{16}$, for isolating peptides binding to specific epitopes of target proteins, using a variant of the protein-catalyzed capture agent (PCC) method ${ }^{17}$. In CET, a chemically synthesized biotin-tagged azide-containing protein fragment, corresponding to the targeted region of a protein, is screened against a comprehensive cyclic One-Bead-One-Compound (OBOC) library of peptides with alkyne handles. Ligands in the correct orientation undergo proximity-catalyzed azide-alkyne cycloaddition reaction and are detected using the biotin label on the epitope. Subsequent binding assays against the full protein identify high-affinity cyclic ligands that bind to a specific protein region. This capability of targeting specific protein regions has allowed the development of high-affinity binders that detect subtle protein structural changes or affect protein functions. Ligands have been developed that selectively bind to phosphorylated active protein ${ }^{18}$, proteins with point mutations ${ }^{19}$, or distinguish between two closely related protein isoforms ${ }^{20}$. Cyclic ligands isolated using this technology has also been utilized to allosterically 
inhibit kinase function ${ }^{19}$, inhibit botulinum toxin uptake in neurons ${ }^{21}$, stabilize the folding of a mutated essential enzyme ${ }^{22}$, and inhibit heme sequestration by Histidine -Rich Protein 2 (HRP2) ${ }^{23}$.

Here, we report on using CET technology to develop a cyclic loop biligand that selectively binds, in vitro, to the phosphorylated Ser474 site of Protein Kinase B (p-Akt2) with high affinity $\left(\mathrm{K}_{\mathrm{D}}=10 \mathrm{nM}\right)$. The cyclic loop biligand consists of a linear peptide joined to a macrocycle peptide through triazole linkage, and was isolated through two iterative in situ screens. The biligand is an allosteric inhibitor of the Akt2 kinase, with an $\mathrm{IC}_{50}$ of $8 \mu \mathrm{M}$. Akt2 can function as an oncoprotein ${ }^{24}$ and is hyperactivated via phosphorylation in many cancers. ${ }^{25-26}$ Thus reagents visualizing and inhibiting p-Akt2 in live cells are useful. We matured this biligand into such a reagent through systematic iterations of its chemical structure to promote cell-penetrating properties, while retaining binding and inhibition selectivity for p-Akt2. Retro-inversion of the cyclic part of the ligand was found to strongly affect cell-penetration properties, while retaining their high affinity for pAkt2. In these two modified ligands. the stereochemistry of two amino acid residues in the macrocycle exhibited strong influence on the extent of the cell penetration. This observation prompted us to explore large-scale $(\sim 40 \mu \mathrm{s})$ molecular metadynamics (metaD) simulations of transport across a lipid bilayer. We find that the stereochemical changes of the threonine side chains in the cyclic part of the biligand permits the ligand molecules to adopt distinctly different conformations and interact differently with the cholesterol in the cell membrane. One of the cellpenetrant biligands interact more with cholesterol, which results in less facile cell-penetration. The other cell-penetrant biligand, which is uptaken to a greater extent by cells, have more intramolecular interactions, and has fewer cholesterol molecules associated with it, which aids in its cell-penetration. While synthetic cyclic polyamine/amide scaffolds ${ }^{27}$ or divalent metal chelate complexes like zinc dipicolylamine have been developed as binders to the phosphoryl group in phosphorylated amino acids, phosphorylated peptides, and phosphorylated proteins in vitro ${ }^{28}$, to the best of our knowledge, this is the first macrocyclic reagent that can selectively recognize a specific phosphoprotein in live cells.

\section{Results}

The development of the cell penetrant anti-pSer474 Akt2 biligand proceeded through three phases: a) the development and optimization of an epitope targeted peptide macrocycle ligand $\left(\mathbf{C}_{\mathbf{i}}\right)$;

b) the extension of that macrocycle into a linked macrocycle - linear peptide $\left(\mathbf{C}_{\mathbf{i}}-\mathbf{N}_{\mathbf{j}}-\mathbf{L}_{\mathbf{k}}\right)$, referred to as biligand $\mathbf{B}_{\mathbf{i}, \mathbf{j}, \mathbf{k}}$, through an in situ click screen, and c) the systematic chemical iteration of $\mathbf{B}_{\mathbf{i}, \mathbf{j}, \mathbf{k}}$ to arrive at the final cell penetrant biligand. Throughout this paper, the indices $\mathrm{i}, \mathrm{j}, \mathrm{k}$ are replaced by numbers, with higher numbers representing more advanced variants of the macrocycle peptide $\left(\mathbf{C}_{\mathbf{i}}\right)$, linker $\left(\mathbf{N}_{\mathbf{j}}\right)$, and linear peptide $\left(\mathbf{L}_{\mathbf{k}}\right)$ components of the biligand $\mathbf{B}_{\mathbf{i}, \mathbf{j}, \mathbf{k}}$.

Development of $\mathbf{C}_{\mathbf{i}} \quad$ Macrocycle peptide ligand candidates was initially identified by screening a synthetic, one- bead- one -compound (OBOC) $)^{29}$ two million elements macrocyclic peptide library against the chemical epitope. The chemical epitope, in this case, is a 32 amino acid long peptide representing the unstructured c-terminal region of the Akt2 protein and contains a hydrophobic motif(HF) and the phosphorylated Ser474 residue. Phosphorylation of Ser474 in the 
protein by mTORC2 results in an allosteric, activating influence over the kinase ${ }^{30}$. A scrambled non-phosphorylated form of the chemical epitope is also synthesized, in which eight residues, including Ser474, corresponding to the hydrophobic motif were scrambled. Both peptides were labeled with a biotin tag on their respective C-termini (Scheme SC. 1, Table T. 1). The OBOC macrocyclic library was screened against the non-phosphorylated ${ }^{[1]}$ scrambled chemical epitope, to remove false positives (roughly $10 \%$ of library) binding to the scrambled chemical epitope or the detection reagents (details in SI). The remaining OBOC library was then screened against the phosphorylated synthetic epitope to yield four hits (Table T. 2). These hits were sequenced using Edman degradation, synthesized, and tested for differential binding to the phosphorylated epitope and the non-phosphorylated, scrambled epitope, using an ELISA assay (Figure S.1). The best macrocycle $\mathbf{C}_{1}$ exhibited an $\mathrm{EC}_{50}$ of $120 \mathrm{nM}$ against pAkt $2^{16}$.

We next chemically modified $\mathbf{C}_{\mathbf{1}}$ to optimize its avidity characteristics for pAkt 2 . We verified that the cyclic structure of $\mathbf{C}_{\mathbf{1}}$ had a significant positive effect on binding (Figure S.2). We tested several analogs with varying ring size (Figure S.3, Figure S.4), and varying chemical nature of the ring closing functionality (Figure S.4). The best ligand $\mathbf{C}_{2}$ had the sequence Cy(YYTYTG$\mathrm{rcm}$ ), where Cy implies the cyclic nature of the ligand and $\mathrm{rcm}$ refers to alkenyl ring closing functionality synthesized by Ruthenium catalyzed Ring Closing Metathesis (RCM) reaction between unnatural amino acids $(R)$ - $\alpha$-(7-Octenyl)alanine (r8) and (S)-2-(4-pentenyl)alanine) (S5). $\mathbf{C}_{2}$ exhibited improved affinity ( $\mathrm{EC}_{50} 44 \mathrm{nM}$ ) (Figure $\mathbf{S . 5}$ ) and selectivity relative to $\mathbf{C}_{\mathbf{1}}$ (Figure S.6). Finally, we appended an azide click handle and a biotin tag to $\mathbf{C}_{2}$ (Figure S.7) $\left(\mathbf{C}_{2}-\mathbf{N}_{1}\right)$ in preparation for an in situ click screen ${ }^{[13,14]}$ to extend the ligand into a biligand.

In the in situ click screen, an OBOC linear peptide library with an appended alkyne was first pre-screened against $\mathbf{C}_{\mathbf{2}}-\mathbf{N}_{\mathbf{1}}$. A color change on treatment with an anti-biotin antibody-alkaline phosphatase conjugate and its BCIP substrate identified hits to biotinylated $\mathbf{C}_{2}-\mathbf{N}_{1}$, and these hits were removed. The cleared library was then screened against pAkt 2 incubated with $\mathbf{C}_{\mathbf{2}}-\mathbf{N}_{\mathbf{1}}$. In this way, pAkt2 provides the scaffold to promote the click reaction between $\mathbf{C}_{2}$ and specific secondary linear library elements. (SI, Scheme SC.2, SI Table T.3).

The in situ click screen yielded four hits (SI, Table T.4, Figure S.8). All biligands of formula $\mathbf{C}_{\mathbf{i}}-\mathbf{N}_{\mathbf{j}}-\mathbf{L}_{\mathbf{k}}$ (macrocycle-linker- linear peptide) built from those hits exhibited improved binding to pAkt2 relative to $\mathbf{C}_{\mathbf{2}}$ (Figure S.9). The $\mathrm{EC}_{50}$ of the best binder, $\mathbf{B}_{2,2,1}$, with linear peptide $\mathbf{L}_{1}$ (sequence kyyir; lowercase alphabet designations denote $\mathrm{D}$ amino acids) was $13.6 \mathrm{nM}$ (Figure S.10). We demonstrated that $\mathbf{B}_{2,2,1}$ bound to the p-S474 epitope of pAkt2 through a competitive binding assay against the phospho-specific, commercial monoclonal antibody raised against that same epitope (Figure S.11). B $\mathbf{B}_{2,2,1}$ also selectively binds to pAkt2 relative to inactive (nonphosphorylated) Akt2 and discriminates pAkt2 from closely related isoforms Akt1 and Akt3. (Figure S.12).

We had previously reported on a high affinity $\left(\mathrm{K}_{\mathrm{D}}=10 \mathrm{nM}\right)$ triligand against pAkt2 that was designed to bind adjacent to the pSer474 residue of Akt2. The triligand comprised of 3 linear peptides assembled into a branched structure, and it could be used to modulate the kinase activity 
of $\mathrm{Akt}^{18}$. However, $\mathbf{B}_{\mathbf{2}, 2, \mathbf{1}}$, designed to bind at the pSer474 site, had no such effect on pAkt2 function. We therefore explored chemical modifications of $\mathbf{B}_{\mathbf{2}, 2, \mathbf{1}}$ that might promote pAkt2 inhibition, while retaining high binding avidity. For these modifications, published crystal structures of antibodies bound to phospho-peptide antigens ${ }^{31}$ were studied in detail. Based on those structures, it was hypothesized that flexible amines, appropriately located, might increase binding to the phospho-serine residue. Appending diaminopropanoic acid at the $\mathrm{N}$ terminal of $\mathbf{B}_{\mathbf{2}, 2, \mathbf{1}}$ (to form $\mathbf{B}_{3,2,1}$ ) yielded a biligand with similar affinity for pAkt2, but also with an inhibitory influence over the kinase. The inhibition constant ( $\mathrm{IC}_{50}$ ) was determined to be $8 \mu \mathrm{M}$ by monitoring the phosphorylation of GSK by pAkt2 through both a western blot and a FRET inhibition assay (SI, Figure S. 13).

Figure 1A shows the molecular structure of $\mathbf{B}_{\mathbf{3}, \mathbf{2}, \mathbf{1}}$. The binding constant, $K_{D}$, of $\mathbf{B}_{\mathbf{3}, \mathbf{2}, \mathbf{1}}$ for pAkt2, was measured using fluorescence polarization to be $10 \mathrm{nM}$ (Figure 1B). $\mathbf{B}_{\mathbf{3}, \mathbf{2}, \mathbf{1}}$ was also tested for binding to a panel of active kinases (Figure 1C). It binds to pAkt2 and pAkt1 but shows a preference for binding to pAkt2. It does not bind to kinase inactive Akt2, and shows negligible binding to other kinases involved in the Akt pathway (GSK3 kinase), and to kinases in other related cell signaling pathways like mTOR signaling pathway (p70S6k kinase) ${ }^{32}$, BCR-ABL pathway $(\mathrm{Abl} 2 \text { kinase })^{33}$, and MAP kinase pathway (MEK1 kinase $)^{34}$ frequently disrupted in cancer.

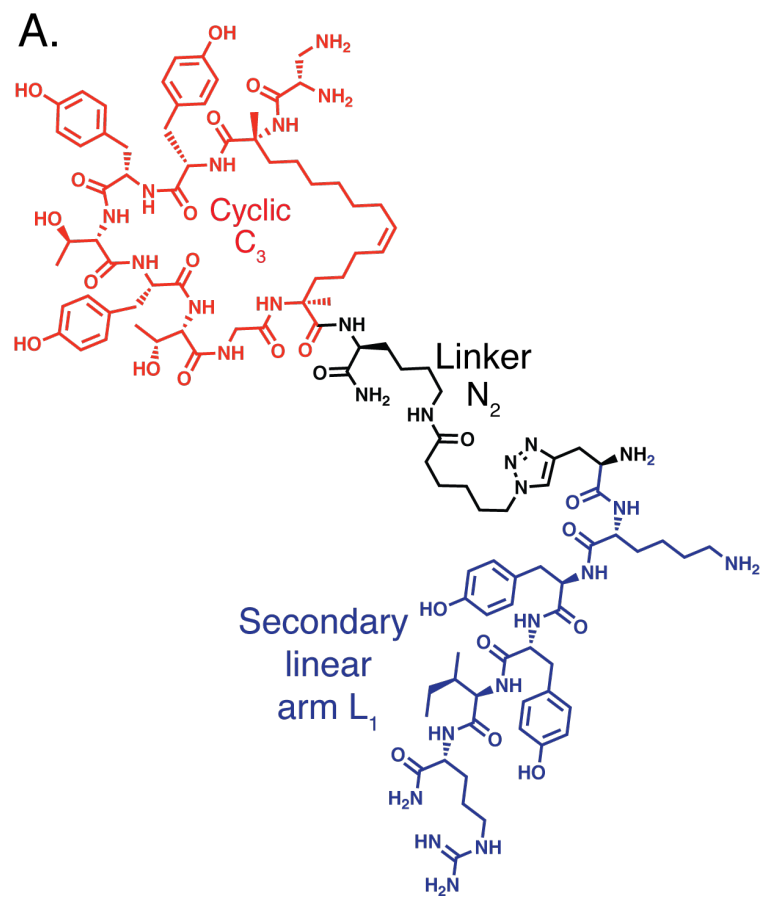

B.
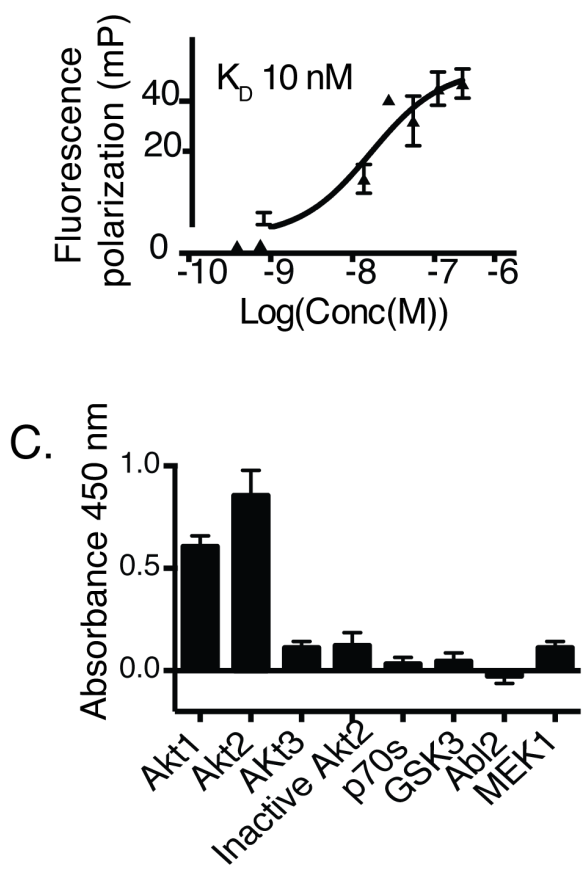

Figure 1: Molecular structure and characteristics of biligand $B_{3,2,1}$.

A. Structure of biligand $\mathbf{B}_{3,2,1}$ consisting of the cyclic component $\mathbf{C}_{\mathbf{3}}$ (red), triazole linker $\mathbf{N}_{2}$ (black) and the linear component $\mathbf{L}_{\mathbf{1}}$ (blue); B. Fluorescence polarization data yielded a dissociation constant $\left(\mathrm{k}_{\mathrm{D}}\right)$ of $\mathbf{B}_{3,2,1}$ for pAkt2 of $10 \mathrm{nM}$; C. Selectivity assays of $\mathbf{B}_{3,2,1}$. Biotinylated $\mathbf{B}_{3,2,1}$ was immobilized on streptavidin plates and probed with His $_{6}$-tagged kinases. Binding was detected by subsequent treatments with $\mathrm{His}_{6}$ antibody complexed with horseradish peroxidase (HRP) and a colorimetric substrate of HRP and quantified by monitoring absorbance at 
$450 \mathrm{~nm}$. Values represent the mean A450 obtained from three experiments, with errors denoted by error bars. $\mathbf{B}_{3,2,1}$ selectively binds to active phosphorylated pAkt2 while showing negligible binding to non-phosphorylated inactive pAkt2.

Following the in vitro optimization of the biligand $\mathbf{B}_{\mathbf{3}, \mathbf{2}, \mathbf{1}}$ its cell-penetrating characteristics were studied. OVCAR3 cells were seeded into glass chambers and starved. Starved cells were treated with $50 \mu \mathrm{M}$ of Ly $294002^{35}$ to reduce the baseline level of pAkt2, and then for induction of cells, wells containing cells were treated with EGF and insulin for 30 minutes at room temperature to induce phosphorylation of Akt. The non-induced cells were not treated with any growth factors. The cells were incubated with fluorescein-labeled $\mathbf{B}_{\mathbf{3}, \mathbf{2}, \mathbf{1}}$ and washed with buffer. Live imaging of stimulated and non-stimulated cells did not detect any fluorescence from the fluorescein label on $\mathbf{B}_{\mathbf{3}, \mathbf{2}, \mathbf{1}}$, indicating that $\mathbf{B}_{\mathbf{3}, \mathbf{2}, \mathbf{1}}$ is not cell-penetrant. Therefore, the next goal was engineering the biligand for cell penetration, while retaining the functional properties that had been achieved in vitro.

\section{Engineering the biligand for cell penetration}

Literature guided chemical modifications were systematically explored to enhance the cell penetrability of biligands while simultaneously verifying that the pAkt2-related functional and avidity characteristics were retained. The chemical modifications included N-methylation of N-H bonds, flourophenylalanine substitutions for tyrosines, retroinversion of the macrocycle, and modifications to the linker that bridges the two peptide moieties (Figure 2). Only the modifications that were incorporated in the final cell-penetrant biligands are discussed below.

An alanine substitution $\operatorname{scan}^{36}$ of $\mathbf{C}_{2}$ revealed that the three tyrosines and the glycine play essential roles in Akt2 binding (Figure S.14). The substitution of the isosteric tyrosine analog 4fluorophenylalanine (4fF) for tyrosine (Figure S.15). The resultant biligand $\mathbf{B}_{4,2,1}$, with two 4fPsubstituted tyrosines, exhibited slightly improved avidity characteristics for p-Akt2. Nmethylation of threonine residues can provide rigidity to the peptide backbone, but attempting that in $\mathbf{C}_{2}$ led to a total loss of binding to pAkt2 (Figure S.16).

The linker $\mathbf{N}_{\mathbf{j}}$ bridging the macrocycle and linear peptide moieties was an integral part of the in situ click screen through which the linear peptide was selected. Ten different chemical modifications designed to alter the rigidity, length, and secondary structure of the linker were explored. Almost all such modifications resulted in the loss of binding avidity for pAkt 2 . Thus, all linkers used in the later developed ligands were based upon the original linker, and are shown in Fig 2. $\mathbf{N}_{\mathbf{1}}$ is the linker used in the in situ click screen, while $\mathbf{N}_{\mathbf{2}}$ is that same linker, but with the triazole formed during the screen incorporated. $\mathbf{N}_{\mathbf{3}}$ is a variant of $\mathbf{N}_{\mathbf{2}}$ that was designed to accommodate the macrocycle moiety when prepared in retroinverted format. Thus, all biligands utilize either $\mathbf{N}_{\mathbf{2}}$ or $\mathbf{N}_{\mathbf{3}}$, depending upon the construction of the macrocycle.

The secondary, linear peptide arm $\mathbf{L}_{\mathbf{k}}$ was, like the macrocycle, modified according to literature guided approaches. Single or multiple N-methylation of amide bonds were explored initially with cyclic arm $\mathrm{C}_{3}$, and linker $\mathrm{N}_{2}$ (biligands $\mathbf{B}_{\mathbf{3}, \mathbf{2}, \mathbf{2}}-\mathbf{B}_{\mathbf{3}, \mathbf{2}, \mathbf{5}}$ ). A triple N-methylated 
derivative $\mathbf{B}_{\mathbf{3}, 2,5}$ was found to be most effective (Figure S.17, Figure S.18). The 4fP-substitution in the macrocycle $\left(\mathrm{C}_{4}\right)$ and triple $\mathrm{N}$-methylation in the linear peptide were combined in the next ligand optimization cycle to make biligand $\mathbf{B}_{\mathbf{4 , 2 , 5}}$. The optimized biligand $\mathbf{B}_{\mathbf{4}, \mathbf{2 , 5}}$ thus had three Nmethylations in the linear $\mathrm{L}_{\mathrm{k}}$ arm and two 4fP substitutions in the macrocycle (Figure S.19), and it exhibited good affinity for pAkt2 (Figure S.20) with an $\mathrm{EC}_{50}$ of 60.6 nM.

Finally, the retroinversion of the cyclic moiety of $\mathbf{B}_{4,2,5}$ was explored. Retroinversion involves inverting the sequence of the peptide and inverting the chirality of the amino acids of the peptide. When $\mathbf{C}_{5}$, the retroinverted version of $\mathbf{C}_{4}$ (see Figure $\mathbf{S . 2 1}$ ) was incorporated in the biligand, the linker $\mathrm{N}_{3}$ and secondary arm were linked to the $\mathrm{C}$ terminal of $\mathbf{C}_{5}$ rather than at the $\mathrm{N}$ terminal of $\mathbf{C}_{\mathbf{4}}{ }^{37}$. Two biligands $-\mathbf{B}_{\mathbf{5 , 3 , 4}}$ and $\mathbf{B}_{\mathbf{5 , 3 , 5}}$ - containing $\mathbf{C}_{\mathbf{5}}$ and di-N-methylated ( $\left.\mathrm{L}_{4}\right)$ or tri$\mathrm{N}$-methylated $\left(\mathrm{L}_{5}\right)$ linear components were synthesized. A biligand $\mathbf{B}_{6,3,5}$ containing a retroinverted cyclic component $\mathbf{C}_{6}$ with $\mathrm{C}$ terminal D-dap (Figure S.22) was also synthesized. Finally, $\mathrm{B}_{7,3,5}$, similar to $\mathrm{B}_{5,3,5}$ except at the $\beta$ carbons on both threonines was designed with $\mathrm{R}$ chirality, which reproduced the correct retro-inverted topological orientation of the $\mathbf{C}_{\mathbf{4}}$ macrocycle. $\mathbf{B}_{\mathbf{5}, \mathbf{3}, \mathbf{4}}, \mathbf{B}_{\mathbf{5}, \mathbf{3}, \mathbf{5}}$, $\mathbf{B}_{\mathbf{6 , 3}, \mathbf{5}}$, and $\mathbf{B}_{7,3,5}$ all bound pAkt with $\mathrm{EC}_{50}$ values near $10 \mathrm{nM}$ (Figure S.23, Figure S.24), and so were about equal to the original biligand $\mathbf{B}_{\mathbf{2}, \mathbf{2}, \mathbf{1}}$ and superior to the non-retroinverted biligand $\mathbf{B}_{\mathbf{4}, \mathbf{2 , 5}}$. These biligands were taken forward for cell penetration studies. Figure $\mathbf{2}$ summarizes all modifications that were done on biligand $\mathbf{B}_{\mathbf{2}, \mathbf{2}, \mathbf{1}}$.

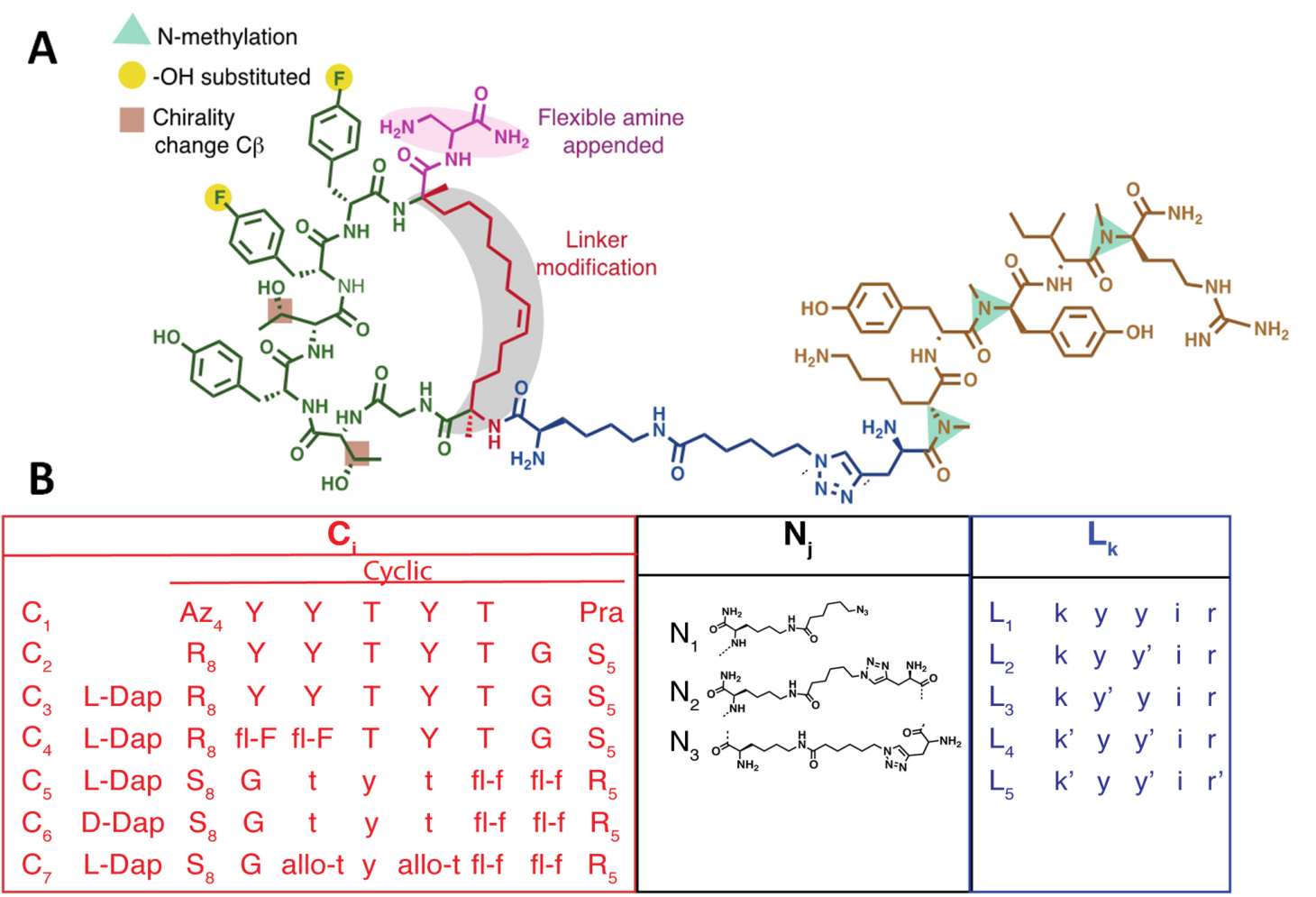

fl-F: L-4-fluorophenylalanine; fl-f: D-4-fluorophenyl-alanine; Dap: Diaminopropanoic acid; allo-t:D-allothreonine; k':N-methyl-D-lysiney':N-methyl-D-tyrosine, r': :N-methyl-D-arginine; small case letters denote $\mathrm{D}$ amino acids.

Figure 2: Biligand modifications to incorporate cell penetration characteristics. A. Structure of best biligand $\mathbf{B}_{7,3,5}$, with chemical iterations, indicated; B. A list of the explored chemical iterations for the 
macrocycle $\left(\mathbf{C}_{\mathbf{i}}\right)$, the linker $\left(\mathbf{N}_{\mathbf{j}}\right)$ and the linear branch $\left(\mathbf{L}_{\mathbf{k}}\right)$. Biligands were named $\mathbf{B}_{\mathbf{i}, j, \mathbf{k}}$. The original ring closing triazole linkage in the cyclic component $\mathbf{C}_{\mathbf{1}}$ was replaced by a hydrophobic allyl linker (gray) in $\mathbf{C}_{\mathbf{2}}$ to facilitate cell penetration. Replacement of tyrosines by isosteric 4-fluorophenylalanine (4fP) (yellow) in $\mathbf{C}_{4}$ increased binding and protease stability. Appending a flexible amine (pink) at the $\mathrm{N}$ terminal of cyclic component $\mathbf{C}_{4}$ increased phospho-selectivity and promoted pAkt2 kinase inhibition. $\mathrm{C}_{5}, \mathrm{C}_{6}$, and $\mathrm{C}_{7}$ represents retroinverted macrocycles.

\section{Cell Penetration Assays}

The cell penetration characteristics of the biligand were studied using several assays. Visualization of cell penetration requires the appendage of a dye, which can influence the penetration characteristics itself. Thus, evidence of cell penetration through functional assays was sought, in which live OVCAR3 cells were treated with biligands, and assayed for inhibition of pAkt. OVCAR3 cells are an ovarian carcinoma cell line that expresses high levels of Akt. Epidermal growth factor (EGF) stimulation of these cells leads to phosphorylation of Akt. To this end, cells were serum starved, treated for 12 hours at $37^{\circ} \mathrm{C}$ with $20 \mu \mathrm{M}$ unlabeled ligands $\mathbf{B}_{\mathbf{5 , 3 , 4}}$, $\mathbf{B}_{\mathbf{5}, 3,5}$, and $\mathbf{B}_{\mathbf{6}, 3,5}$. The ligands were thoroughly washed off, and the cells were treated with EGF and insulin and lysed (Figure 3A). Inhibition of pAkt is known to repress the phosphorylation level of its downstream effector GSK3 (pGSK3), and so levels of pGSK3 were probed in the cell lysate using western blotting. Promising results were found only for the retroinverted biligand $\mathbf{B}_{5,3,5}$ (Figure 3B, Figure S.25). The cell penetration characteristics of dye-labeled $\mathbf{B}_{\mathbf{5}, \mathbf{3 , 5}}$ and its close analog $\mathbf{B}_{7,3,5}$ were, therefore, compared using fluorescence microscopy. These two biligands exhibited nearly identical binding affinities for pAkt and differed only in the stereochemistry of the $\beta$-carbons of the two threonines.

In Figure 3B fluorescence microscopy results of stimulated OVCAR3 cells treated with $100 \mathrm{nM}$ of $\mathbf{B}_{\mathbf{5}, 3,5}$ (left row) and $\mathbf{B}_{\mathbf{7}, 3,5}$ are presented. These data indicate that $\mathbf{B}_{7,3,5}$ exhibits superior cell penetration relative to $\mathbf{B}_{\mathbf{5 , 3}, \mathbf{5}}$. In addition to cytosolic penetration, distinct punctate formation for $\mathbf{B}_{7,3,5}$ was observed, which indicated the peptide had penetrated the cytosol and some of it had accumulated in endosomal vesicles. This observation is consistent with previous observations of uptake of low concentrations of cell-penetrating peptides such as nona-arginine by endocytosis ${ }^{38}$. When the cells were not stimulated, little penetration was observed, indicating that neither biligand was retained within the cell in a significant amount when pAkt levels are low. When the cells were treated with a higher concentration of the biligands $(200 \mathrm{nM})$, the differential performance of the biligands was still readily discerned (Figure S.26). 
A
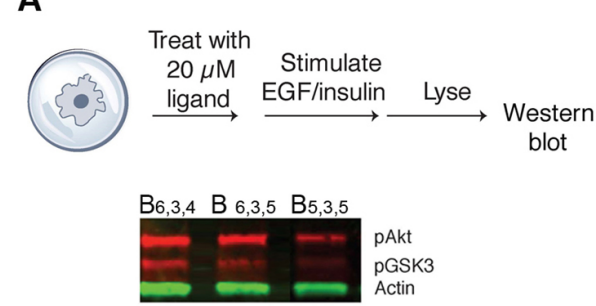

C
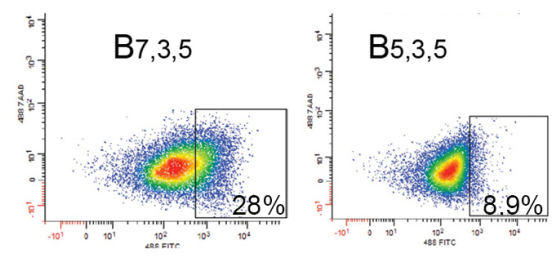

D

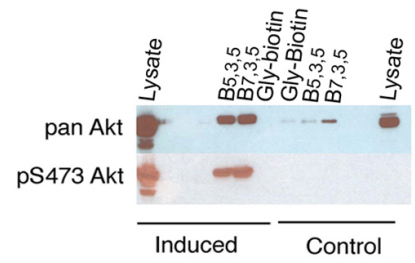

B
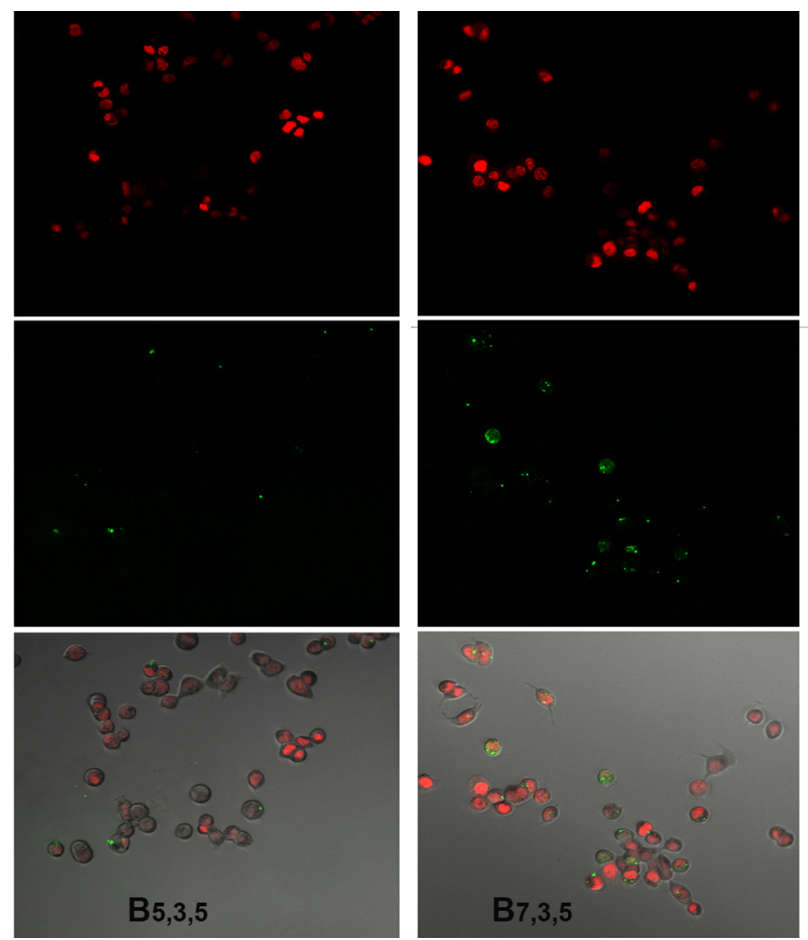

Figure 3: Cell penetration assays of selected retroinverted biligands. A. Functional assay to interrogate for the inhibition of pAkt and its downstream effector, pGSK3, via cell penetrant biligands. Live cells were treated with unlabeled biligand, washed to remove extracellular biligand, stimulated with EGF and insulin, lysed, analyzed using gel electrophoresis and western blot. The levels of pAkt at S474 and the level of phosphorylation of Akt substrate GSK3 were probed using pAkt and pGSK3 rabbit antibodies and Alexa Fluor 790 conjugated anti-rabbit secondary antibody. Loading control actin was quantified using a mouse actin antibody and Alexa Fluor 790 conjugated anti-mouse secondary antibody. This data shows that $\mathbf{B}_{\mathbf{5 , 3 , 5}}$ is a cell-penetrant inhibitor of pAkt2, while biligands $\mathbf{B}_{\mathbf{6 , 3}, \mathbf{4}}$ and $\mathbf{B}_{\mathbf{6 , 3 , 5}}$ are not inhibitors or not cell penetrant; $\mathrm{B}$. Fluorescence micrographs of stimulated OVCAR3 cells treated with $100 \mathrm{nM}$ of fluorophore-labeled $\mathbf{B}_{\mathbf{5 , 3 , 5}}$ (left column) and the near structural isomer $\mathbf{B}_{7,3,5}$. The top, middle, and bottom row images correspond to the nuclear stain, fluorescent biligand, and combined bright field and fluorescence images; C. Flow cytometry experiments of live, stimulated OVCAR3 cells treated with $\mathbf{B}_{\mathbf{5 , 3 , 5}}$ and $\mathbf{B}_{\mathbf{7 , 3 , 5}}$ reveal that $\mathbf{B}_{7,3,5}$ exhibits superior cell penetration characteristics; D. Use of biligands as phospho-specific antibody-equivalents for phosphoAkt 2 immunoprecipitation. OVCAR3 cells were serum starved, then induced with EGF or treated with a PI3K inhibitor Ly294002 (control). The cell lysate was immunoprecipitated using biotinylated biligands $\mathrm{B}_{5,3,5}$ and $\mathrm{B}_{7,3,5}$ immobilized on streptavidin-agarose beads, and probed for total Akt, and active Akt 1 / Akt2 phosphorylated at S473 / S474, by treatment with a pan Akt antibody and $\mathrm{pS} 473 / \mathrm{pS} 474 \mathrm{Akt} 1 / \mathrm{Akt} 2$ antibody respectively.

The relative cell penetration characteristics of fluorescein-labeled $\mathbf{B}_{5,3,5}$ and $\mathbf{B}_{7,3,5}$ were next quantified using flow cytometry (Fig 3C). The biligands were incubated at 200nM with live OVCAR3 cells. The flow cytometry results showed significantly higher cellular uptake of $\mathbf{B}_{7,3,5}$ ( $28 \%$ vs $8.9 \%$ ), consistent with the fluorescence microscopy observations.

As a final assay, the use of $\mathbf{B}_{5,3,5}$ and $\mathbf{B}_{7,3,5}$ as pAkt2 immunoprecipitation reagents was explored. Immunoprecipitation of the cell lysates from both stimulated and non-stimulated OVCAR3 by agarose bound $\mathbf{B}_{5,3,5}$ and $\mathbf{B}_{7,3,5}$ followed by western blotting revealed that although $\mathbf{B}_{7,3,5}$ exhibited slightly better performance (Figure 3D), both ligands efficiently and selectively pulled down pAkt2 from the lysed cells. Thus, the two ligands exhibited high affinity and 
selectivity for pAkt2, while $\mathbf{B}_{7,3,5}$ exhibited superior cell penetration characteristics. The superior cell penetration characteristics might have been attributed to the stereochemistry of the $\beta$-carbons on the two threonine residues in the macrocycle moiety. To investigate this, we performed molecular metaD simulations of cell penetration for these two biligands. For the metadynamics simulations analysis, the highlighted allo-threonine in $\mathrm{C}_{7}$ with cyclic sequence $\left(\mathrm{S}_{8} \mathrm{G}\right.$ allo-t y allo$\mathrm{t}$ fl-f fl- $\mathrm{R}_{5}$ ) was designated as chiral center $1(\mathrm{CC} 1)$ in $\mathrm{B}_{7,3,5}$, whereas the highlighted $\mathrm{D}$-threonine in $\mathrm{C}_{5}$ with cyclic sequence $\left(\mathrm{S}_{8} \mathrm{G} \boldsymbol{t} \mathrm{y}\right.$ t fl-f fl-f $\mathrm{R}_{5}$ ), was designated as $\mathrm{CC} 1$ in $\mathrm{B}_{5,3,5}$. Chiral center 2 (CC2) correspond to the highlighted allo-threonine in $\mathrm{C}_{7}\left(\mathrm{~S}_{8} \mathrm{G}\right.$ allo-t y allo- $t$ fl-f fl- $\mathrm{f} \mathrm{R}_{5}$ ) for ligand $\mathrm{B}_{7,3,5}$ and to highlighted d-threonine in $\mathrm{C} 5\left(\mathrm{~S}_{8} \mathrm{G}\right.$ t $\mathrm{y} t \mathrm{fl}-\mathrm{f}$ fl-f $\left.\mathrm{R}_{5}\right)$ for ligand $\mathrm{B}_{5,3,5}$.
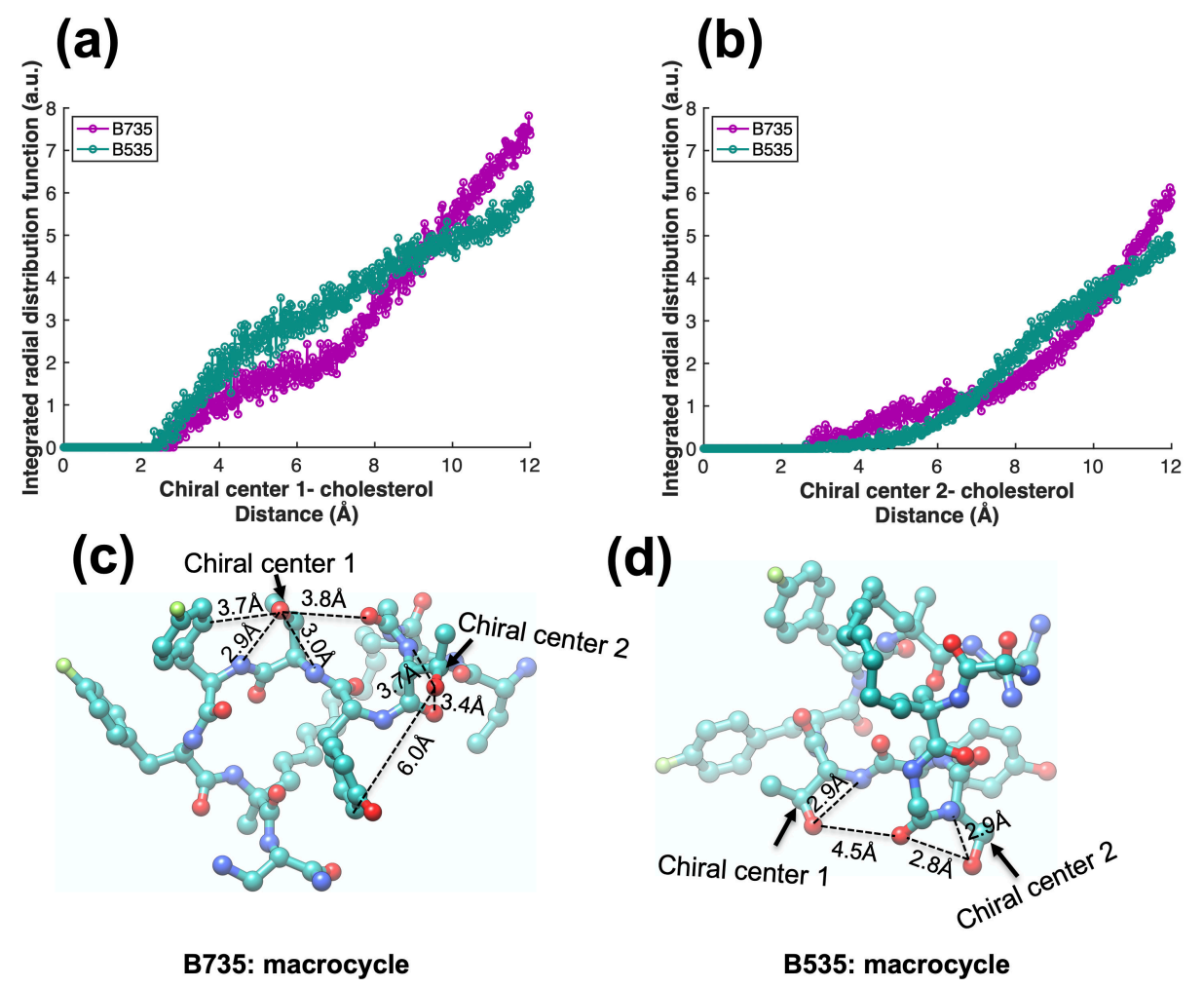

(d)

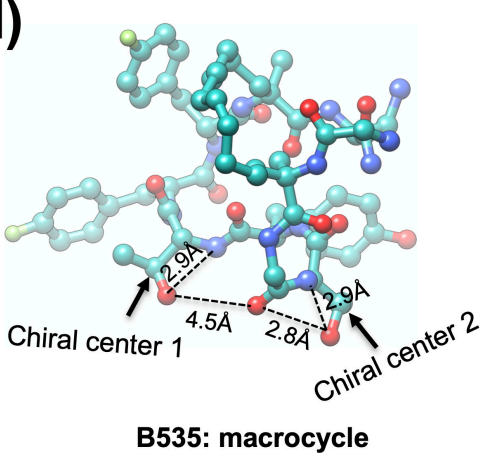

Figure 4. Cholesterol interactions with the enantiomeric threonine residues profoundly affect the cell penetration of the biligands.

The integrated radial distribution analysis near the transition state of (a) the chiral center 1 with cholesterol, (b) the chiral center 2 with cholesterol. Integrating over distances up to 7.5 A shows that $\mathrm{B}_{5,3,5}$ chiral center 1 (CC1) interacts with $\sim 4$ atoms of the cholesterol molecule within the lipid membrane, whereas $\mathrm{B}_{7,3,5}$ chiral center 1 interacts with $\sim 2.5$ atoms. This additional 1.5 interaction leads to slowing the diffusion for $\mathrm{B}_{5,3,5}$ compared to $\mathrm{B}_{7,3,5}$. The optimized conformation of the biligand macrocycles near the transition state during their cell penetration obtained from long-timescale (an aggregate of $\sim 34 \mu \mathrm{s}$ ) metadynamics simulations: (c) $\mathrm{B}_{7,3,5}$ : the chiral centers interact mostly with polar atoms within the macrocycle. This decreases the number of attractive interactions of the chiral centers available to interact with cholesterols, and (d) $B_{5,3,5}$ : the chiral polar centers are mostly exposed to lipid, increasing the interactions with cholesterol molecules. All reported distances (Figure $4 \mathrm{c} \& 4 \mathrm{~d}$ ) were averaged over the whole trajectory of transition state of biligands ( $>400 \mathrm{~ns}$ ) during the trans membrane diffusion.

\section{Computational Simulations of Cell Penetration}


The differential cell penetrating characteristics of ligands $\mathbf{B}_{5,3,5}$ and $\mathbf{B}_{7,3,5}$ were explored using well-tempered metaD simulations ${ }^{39}$. We performed metaD calculations using periodic simulation boxes containing one biligand $\left(\mathbf{B}_{5,3,5}\right.$, or $\left.\mathbf{B}_{7,3,5}\right), \sim 6500$ water molecules, biological level of $\mathrm{NaCl}(0.15 \mathrm{M} \cong 34$ ions), and a lipid bilayer containing 35 POPC molecules in each leaflet with $20 \%$ cholesterol content ( 7 cholesterol molecules in each leaflet). The total number of atoms in the simulation is $\sim 30,000$ atoms. To address how the stereochemistry of the two threonine residues in the macrocycle influences cell penetration, we examined the binding to the membrane surface relative to solvent and we examined the molecular transfer across the lipid membrane (Figure S27a).

\section{Binding to the surface from solution}

Here we examined the binding of the biligand to the membrane surface relative to the bulk solution. Thus, we adjusted the charge of the biligands to the physiological $\mathrm{pH}$ (7.4). To prepare the system for free energy calculations, we first minimized the simulation box using the steepest descent algorithm with positional restraints on heavy atoms while allowing the POPC/cholesterol molecules to move freely along the xy-plane. We then gradually (over $2 \mathrm{~ns}$ ) removed restraints on the biligand, POPC, and cholesterol, and performed a $\sim 100$ ns equilibration to relax the simulation box. To evaluate the energetics associated with the solution of $\mathbf{B}_{5,3,5}$, and $\mathbf{B}_{7,3,5}$ on the membrane surface, we employed metaD free energy calculations for $\sim 3 \mu$ s (Figure S27b). During these calculations, collective variables (CV) were chosen as:

i) the z-component (diffusion direction, shown in Figure S27) of the distance between the center of mass of macrocycle to the center of mass of lipid membrane

ii) the z-component of the distance between the center of mass of linear branch to the center of mass of lipid membrane.

We find that the biligands exhibit similar affinity to the membrane bilayer $(\Delta \mathrm{G}=-5.0 \pm 0.1$ $\mathrm{kcal} / \mathrm{mol}$ ). Thus, the difference in stereochemistry of threonine residues on the macrocycle segment has negligible influence on the dynamics of the biligands on the membrane surface (Figure S27b). These calculations suggest that the differential in the cell penetration of biligands exclusively is associated with trans membrane diffusion.

\section{Trans Membrane diffusion}

For the trans membrane diffusion we modified the protonation state of the residues to be appropriate for a low dielectric constant medium. Thus, we adjusted the net charge of each biligand to its neutral state for the course of free energy calculations.

Here we started with the optimum position of biligands on the membrane surface, determined from the free energy calculations at the solution surface. To examine migration of either $\mathbf{B}_{5,3,5}$ or $\mathbf{B}_{7,3,5}$ through the membrane, we performed an aggregate of $\sim 34 \mu$ s metaD free energy calculations (Figure S27c), During this penetration, our main aim was to evaluate the energy barrier $\left(\Delta \mathrm{G}^{\dagger}\right)$ of diffusion across the membrane since the energy barrier controls the diffusion rate of bioligands [diffusion coefficient $\propto \exp \left(-\Delta \mathrm{G}^{\dagger} / \mathrm{RT}\right)$.

Our free energy calculations (Figure S27c) find that the free energy barrier to diffuse from one surface to the other membrane surface is: 
For $\mathbf{B}_{7,3,5}: \Delta \mathrm{G}^{\dagger}=22.2 \pm 0.3 \mathrm{kcal} / \mathrm{mol}$ )

For $\mathbf{B}_{5,3,5}: \Delta \mathrm{G}^{\dagger}=22.5 \pm 0.1 \mathrm{kcal} / \mathrm{mol}$ )

Thus, $\mathbf{B}_{\mathbf{7 , 3}, 5}$ is predicted to have a higher penetration than $\mathbf{B}_{\mathbf{5 , 3 , 5}}$, which is consistent with our flow cytometry results.

To identify an atomistic mechanism by which the chirality might influence diffusion, we examined a number of possible descriptors that did not lead to significant differential affects, as shown in Figure S.28. The only difference we could find that correlated with the observed difference in diffusion rate involves the interactions between chiral center $1(\mathrm{CC} 1)$ and cholesterol. Figure $4 \mathrm{AB}$ show that integrating the radial distribution from $\mathrm{CC} 1$ over distances up to $7.5 \mathrm{~A}$ that $\mathrm{B}_{5,3,5} \mathrm{CC} 1$ interacts with $\sim 4.0$ atoms of the cholesterol molecule within the lipid membrane, whereas $\mathrm{B}_{7,3,5} \mathrm{CC} 1$ interacts with $\sim 2.5$ atoms. For $\mathrm{CC} 2$ we see little differential effect. This additional interaction of $\mathrm{CC} 1$ for $\mathrm{B}_{5,3,5}$ with 1.5 extra atoms of the cholesterol molecule slows the diffusion compared to $\mathrm{B}_{7,3,5}$, explaining the observed difference in diffusion rate.

To gain mechanistic insight into why $\mathrm{CC} 1$ for $\mathrm{B}_{5,3,5}$ interacts with additional atoms of the cholesterol molecule, we examined the structures of the macrocycle for structures corresponding to the peak in the free energy, the transition state (Figure S.29). The analysis of the non-bonded interaction energies shows that the significant difference in the cell penetration arises from a delicate balance of interactions between the macrocycle and cholesterol molecules. Thus, Figure S29b shows that the macrocycle of $\mathbf{B}_{7,3,5}$ establishes $\sim 3 \mathrm{kcal} / \mathrm{mol}$ stronger interactions with cholesterol. However, these stronger interactions arise mostly from the body of the macrocycle rather than the chiral centers.

To understand the origin of the stronger interaction of $\mathrm{B}_{5,3,5}$ with cholesterol in the transition state region, Figure $\mathbf{4 C D}$ examines their structures. We see that $\mathbf{B}_{\mathbf{7}, 3,5}$ adopts conformations that allow $\mathrm{CC} 1$ to enhance internal polar interactions, making them less available to interact with the cholesterol. On the other hand, $\mathbf{B}_{5,3,5}$ adopts conformations that expose the polar residues to cholesterol (Figure 4D), resulting in additional interactions, as shown in Figure 5AB. The net result as indicated above is that $\mathrm{CC} 1$ of $\mathrm{B}_{5,3,5}$ establishes $\sim 1.5$ more interactions than does the $\mathrm{CC} 1$ of $\mathrm{B}_{7,3,7}$ with the cholesterol molecules within $7.5 \AA$ distance from $\mathrm{CC} 1$. This extra drag on $\mathbf{B}_{5,3,5}$ increases the friction for the diffusion compared to $\mathbf{B}_{7,3,5}$. 

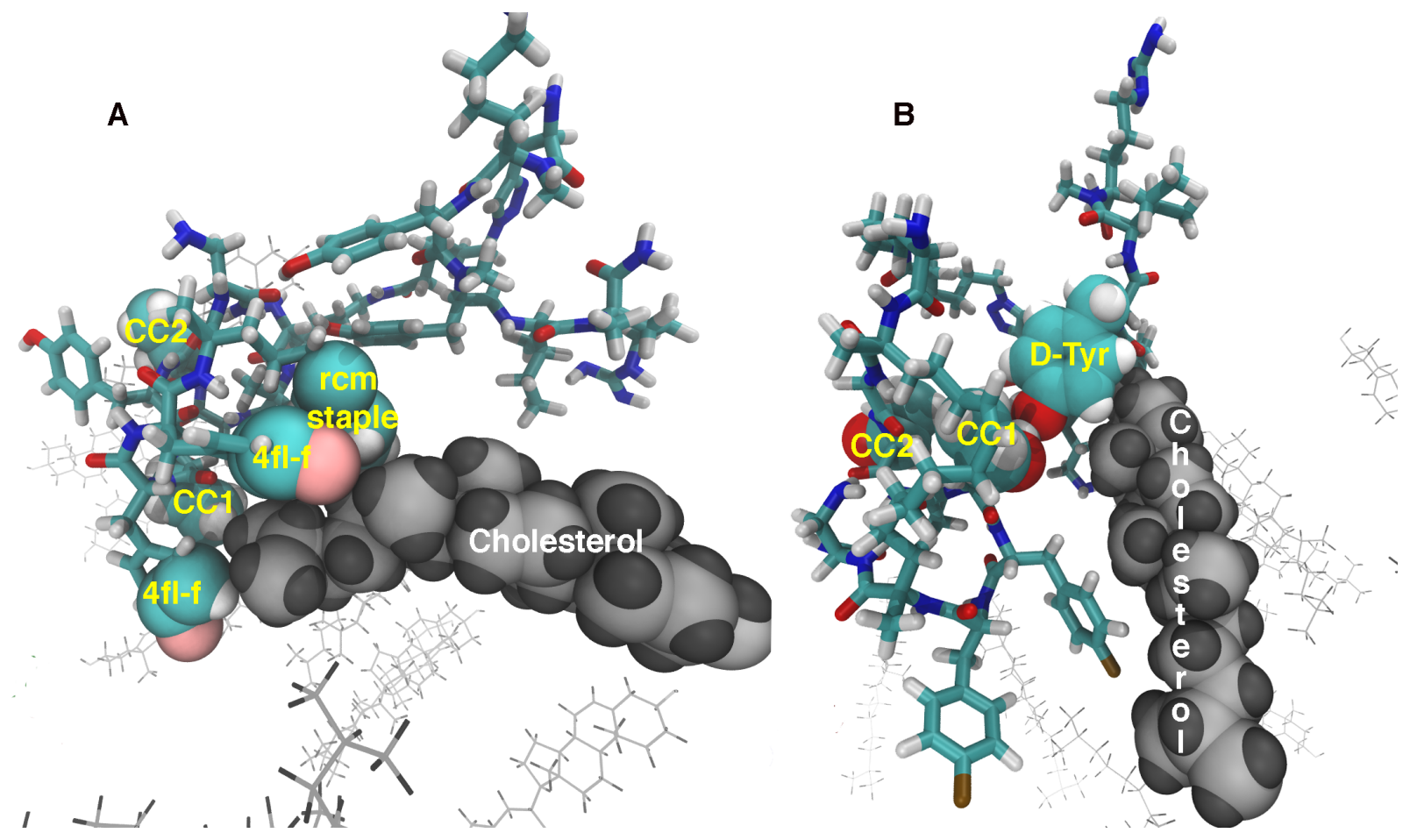

Figure 5: $B_{5,3,5}$ chiral center 1 (CC1) recruits other parts of the ligand to have additional interactions with cholesterol. A. In $\mathrm{B}_{5,3,5}$, the $\mathrm{CC} 1$, the two 4Fl-Phe and the $\mathrm{rcm}$ staple in $\mathbf{C}_{5}$ form a nest where a cholesterol binds through hydrophobic interactions; B. The hydroxyl side chain of Thr in $\mathrm{CC} 1$ forms a hydrogen bond with the phenolic oxygen of D-Tyr in the linear $\mathrm{L}_{5}$ portion of $\mathrm{B}_{5,3,5}$ biligand and orients the D-Tyr to interact favorably with cholesterol. The second chiral center $\mathrm{CC} 2$ does not interact with $\mathrm{CC} 1$ or cholesterol in these conformations. Molecular conformations are shown near the transition state during the cell penetration of $\mathbf{B}_{\mathbf{5}, 3,5}$ ligand. $\mathbf{B}_{\mathbf{5}, \mathbf{3 , 5}}$ is shown in blue, with regions interacting with cholesterol shown as van der Waals spheres. Cholesterol is shown in grey, and the cholesterol interacting with $\mathrm{B}_{5,3,5}$ is shown in VDW representation, using VMD software.

\section{Discussion:}

While there is a significant interest in developing macrocyclic ligands as therapeutics probes and drug candidates targeting intracellular proteins, any definitive guidelines for developing ligands that have the desired function and can penetrate cells are yet to be established, unlike the Lipinski's rules for small molecules. One can incorporate multiple arginines as a part of the cyclic peptide library during the screening process ${ }^{40}$, but this increases the size of the ligand without contributing to the library diversity. Here, we isolated, though Chemical Epitope Targeting screening, a ligand specific for phosphorylated Akt, and then made this ligand cell-penetrant, while retaining its affinity for pAkt. We used techniques such as alanine scan, N-methylation and retroinversion to achieve our goal. Alanine scan of the cyclic $\mathrm{C}_{\mathrm{i}}$ decreased the binding of the ligand to pAkt2 and revealed the importance of each amino acid. The tyrosine in $\mathrm{C}_{\mathrm{i}}$ could be replaced by a homologous amino acid, fluorophenylalanine, without decreasing the binding for pAkt2. N-methylation of cyclic $\mathrm{C}_{\mathrm{i}}$ destroyed the binding affinity for the protein, so the flexibility of the amide bonds is important for protein affinity. N-methylation of the linear part $\mathrm{L}_{\mathrm{k}}$, which makes the amide bonds 
more rigid but is much less restrictive overall, due to the linear nature of the ligand, did not have a deleterious effect on binding to pAkt2. Any change in linker length or properties such as increased charge or helix induction destroyed the ligand affinity for pAkt2. Retroinversion of the cyclic $\mathrm{Ci}$ part allowed the biligands to retain their high affinities for pAkt2, a critical criterion. Retro-inversion of $\mathrm{C}_{\mathrm{i}}$ contributed to effective cell penetration by the biligands, probably because of the enhanced stability of the resultant D-amino acid containing biligands to cellular proteases.

While a crystal structure of pAkt2 with the ligand would have significantly helped in directing our studies, the pS474 region of Akt 2 is disordered, and the structure of this region is not well-resolved in high resolution crystal structures of Akt. It should be noted that disordered loops are known to play critical roles in kinases ${ }^{41}$, and so developing a reagent targeting the disordered loop can have functional properties, such as the kinase inhibition we achieve with $\mathrm{B}_{535}$. Two retroinverted biligands, $\mathbf{B}_{\mathbf{7}, 3,5}$ and $\mathbf{B}_{\mathbf{5}, 3,5}$, were found to penetrate cells and bind to pAkt2 specifically. $\mathbf{B}_{7,3,5}$ and $\mathbf{B}_{5,3,5}$ vary only in the chiral centers $\mathrm{CC} 1$ and $\mathrm{CC} 2$, the two threonine side chains in cyclic part $\mathrm{Ci}$, but this, surprisingly, has a significant effect $(3 \mathrm{x})$ on the level of uptake of the ligands by the cells. To investigate this phenomenon, we did metadynamics simulations to evaluate the membrane uptake, followed by the membrane trans diffusion of $\mathbf{B}_{7,3,5}$ and $\mathbf{B}_{5,3,5}$. In line with our flow cytometry observations, our free energy estimations showed that $\mathrm{B}_{735}$ has a lower energy barrier to diffuse from one surface to the other membrane surface, confirming that $\mathrm{B}_{735}$ has superior penetration over $\mathbf{B}_{\mathbf{5}, 3,5}$. The dramatic difference in penetration originates from the orientation of chiral centers $\mathrm{CC} 1$ and $\mathrm{CC} 2$ and their interactions with the membrane components. During the transmembrane diffusion, the chiral centers $\mathrm{CC} 1$ and $\mathrm{CC} 2$ in $\mathbf{B}_{7,3,5}$ are more involved with internal polar interactions, making them less available to interact externally with the cholesterol. Our results thus support the well-established hypothesis in literature that the ability to form internal hydrogen bonds is critical for passive membrane permeability ${ }^{42}$. In contrast, the chiral centers of $B_{535}$ are externally engaged with cholesterol molecules (1.5x interactions), producing extra drag on $\mathbf{B}_{5,3,5}$ that increases the friction for the diffusion compared to $\mathbf{B}_{7,3,5}$.

Acknowledgments: The various PCCs reported here were developed under funding from the National Cancer Institute through grant \#1U54 CA199090-01 (JRH PI). WAG and AM thank NIH (NIH R35HL150807) for support.

Competing Interests: JRH is a founder and board member of Indi Molecular, which is a company seeking to commercialize PCC technology. 
References:

1. Hunter, T., Protein kinases and phosphatases: The Yin and Yang of protein phosphorylation and signaling. Cell 1995, 80 (2), 225-236.

2. Blume-Jensen, P.; Hunter, T., Oncogenic kinase signalling. Nature 2001, 411 (6835), 355365.

3. Hennessy, B. T.; Smith, D. L.; Ram, P. T.; Lu, Y.; Mills, G. B., Exploiting the PI3K/AKT pathway for cancer drug discovery. Nat Rev Drug Discov 2005, 4 (12), 988-1004.

4. Hayat, M. A., Handbook of Immunohistochemistry and in Situ Hybridization of Human Carcinomas: Molecular Pathology, Colorectal Carcinoma, and Prostate Carcinoma. 2005.

5. Thurber, G. M.; Schmidt, M. M.; Wittrup, K. D., Antibody tumor penetration: Transport opposed by systemic and antigen-mediated clearance. Advanced drug delivery reviews 2008, 60 (12), 1421-1434.

6. Craik, D. J.; Fairlie, D. P.; Liras, S.; Price, D., The Future of Peptide-based Drugs. Chemical biology \&amp; drug design 2012, 81 (1), 136-147.

7. G Fricker, A. F., Mechanisms of hepatic transport of cyclosporin A: an explanation for its cholestatic action? The Yale journal of biology and medicine 1997, 70 (4), 379-390.

8. White, T. R.; Renzelman, C. M.; Rand, A. C.; Rezai, T.; McEwen, C. M.; Gelev, V. M.; Turner, R. A.; Linington, R. G.; Leung, S. S. F.; Kalgutkar, A. S.; Bauman, J. N.; Zhang, Y.; Liras, S.; Price, D. A.; Mathiowetz, A. M.; Jacobson, M. P.; Lokey, R. S., On-resin N-methylation of cyclic peptides for discovery of orally bioavailable scaffolds. Nature chemical biology 2011, $7(11)$, 810-817.

9. Beck, J. G.; Chatterjee, J.; Laufer, B.; Kiran, M. U.; Frank, A. O.; Neubauer, S.; Ovadia, O.; Greenberg, S.; Gilon, C.; Hoffman, A.; Kessler, H., Intestinal Permeability of Cyclic Peptides: Common Key Backbone Motifs Identified. J Am Chem Soc 2012, 134 (29), 12125-12133.

10. Milletti, F., Cell-penetrating peptides: classes, origin, and current landscape. Drug Discovery Today 2012, 17 (15-16), 694-704.

11. Cardozo, A. K.; Buchillier, V.; Mathieu, M.; Chen, J.; Ortis, F.; Ladrière, L.; Allaman-Pillet, N.; Poirot, O.; Kellenberger, S.; Beckmann, J. S.; Eizirik, D. L.; Bonny, C.; Maurer, F., Cellpermeable peptides induce dose- and length-dependent cytotoxic effects. Biochimica et Biophysica Acta (BBA) - Biomembranes 2007, 1768 (9), 2222-2234.

12. Bockus, A. T.; McEwen, C. M.; Lokey, R. S., Form and function in cyclic peptide natural products: a pharmacokinetic perspective. Curr Top Med Chem 2013, 13 (7), 821-36.

13. Chorev, M.; Goodman, M., A dozen years of retro-inverso peptidomimetics. Accounts of Chemical Research 1993, 26 (5), 266-273.

14. Berman, J. M.; Goodman, M.; Nguyen, T. M.-D.; Schiller, P. W., Cyclic and acyclic partial retro-inverso enkephalinamides: Mu receptor selective enzyme resistant analogs. Biochemical and biophysical research communications 1983, 115 (3), 864-870.

15. Freidinger, R. M.; Colton, C. D.; Perlow, D. S.; Whitter, W. L.; Paleveda, W. J.; Veber, D. F., Modified retro enantiomers are potent somatostatin analogs. Peptides, structure and function 1983, 349-352.

16. Das, S.; Nag, A.; Liang, J.; Bunck, D. N.; Umeda, A.; Farrow, B.; Coppock, M. B.; Sarkes, D. A.; Finch, A. S.; Agnew, H. D.; Pitram, S.; Lai, B.; Yu, M. B.; Museth, A. K.; Deyle, K. M.; Lepe, B.; Rodriguez-Rivera, F. P.; McCarthy, A.; Alvarez-Villalonga, B.; Chen, A.; Heath, J.; Stratis-Cullum, 
D. N.; Heath, J. R., A General Synthetic Approach for Designing Epitope Targeted Macrocyclic Peptide Ligands. Angew Chem Int Ed Engl 2015, 54 (45), 13219-24.

17. Agnew, H. D.; Rohde, R. D.; Millward, S. W.; Nag, A.; Yeo, W. S.; Hein, J. E.; Pitram, S. M.; Tariq, A. A.; Burns, V. M.; Krom, R. J.; Fokin, V. V.; Sharpless, K. B.; Heath, J. R., Iterative in situ click chemistry creates antibody-like protein-capture agents. Angew Chem Int Ed Engl 2009, 48 (27), 4944-8.

18. Nag, A.; Das, S.; Yu, M. B.; Deyle, K. M.; Millward, S. W.; Heath, J. R., A chemical epitopetargeting strategy for protein capture agents: the serine 474 epitope of the kinase Akt2. Angewandte Chemie (International ed. in English) 2013, 52 (52), 13975-13979.

19. Deyle, K. M.; Farrow, B.; Qiao Hee, Y.; Work, J.; Wong, M.; Lai, B.; Umeda, A.; Millward, S. W.; Nag, A.; Das, S.; Heath, J. R., A protein-targeting strategy used to develop a selective inhibitor of the E17K point mutation in the PH domain of Akt1. Nature chemistry 2015, 7 (5), 455-62.

20. Lai, B. T.; Wilson, J. A.; Malette Loredo, J.; Pitram, S. M.; LaBerge, N. A.; Heath, J. R.; Agnew, H. D., Epitope-Targeted Macrocyclic Peptide Ligand with Picomolar Cooperative Binding to Interleukin-17F. Chemistry - A European Journal 2018, 24 (15), 3760-3767.

21. Farrow, B.; Wong, M.; Malette, J.; Lai, B.; Deyle, K. M.; Das, S.; Nag, A.; Agnew, H. D.; Heath, J. R., Epitope targeting of tertiary protein structure enables target-guided synthesis of a potent in-cell inhibitor of botulinum neurotoxin. Angew Chem Int Ed Eng/ 2015, 54 (24), 7114-9. 22. Bunck, D. N.; Atsavapranee, B.; Museth, A. K.; VanderVelde, D.; Heath, J. R., Modulating the Folding Landscape of Superoxide Dismutase 1 with Targeted Molecular Binders. Angew Chem Int Ed Eng/ 2018, 57 (21), 6212-6215.

23. Liang, J.; Bunck, D. N.; Mishra, A.; Hong, S.; Idso, M. N.; Heath, J. R., Inhibition of heme sequestration of histidine-rich protein 2 using multiple epitope-targeted peptides. Journal of Peptide Science 2019, 25 (9), e3203.

24. Lawlor, M. A.; Alessi, D. R., PKB/Akt: a key mediator of cell proliferation, survival and insulin responses? Journal of Cell Science 2001, 114 (16), 2903-2910.

25. Bellacosa, A.; Defeo, D.; Godwin, A. K.; Bell, D. W.; Cheng, J. Q.; Altomare, D. A.; Wan, M. H.; Dubeau, L.; Scambia, G.; Masciullo, V.; Ferrandina, G.; Panici, P. B.; Mancuso, S.; Neri, G.; Testa, J. R., Molecular Alterations of the Akt2 oncogene in ovarian and breast carcinomas International Journal of Cancer 1995, 64 (4), 280-285.

26. Brognard, J.; Clark, A. S.; Ni, Y. C.; Dennis, P. A., Akt/protein kinase B is constitutively active in non-small cell lung cancer cells and promotes cellular survival and resistance to chemotherapy and radiation. Cancer Research 2001, 61 (10), 3986-3997.

27. Wu, B.; Cui, F.; Lei, Y.; Li, S.; de Sousa Amadeu, N.; Janiak, C.; Lin, Y.-J.; Weng, L.-H.; Wang, Y.-Y.; Yang, X.-J., Tetrahedral Anion Cage: Self-Assembly of a (PO 4) 4L 4Complex from a Tris(bisurea) Ligand. Angew Chem 2013, 125 (19), 5200-5204.

28. Anai, T.; Nakata, E.; Koshi, Y.; Ojida, A.; Hamachi, I., Design of a hybrid biosensor for enhanced phosphopeptide recognition based on a phosphoprotein binding domain coupled with a fluorescent chemosensor. J Am Chem Soc 2007, 129 (19), 6232-6239.

29. Lam, K. S.; Lebl, M.; Krchnak, V., The "One-Bead-One-Compound" Combinatorial Library Method. Chem Rev 1997, 97 (2), 411-448. 
30. Yang, J.; Cron, P.; Good, V. M.; Thompson, V.; Hemmings, B. A.; Barford, D., Crystal structure of an activated Akt/protein kinase B ternary complex with GSK3-peptide and AMPPNP. Nat Struct Biol 2002, 9 (12), 940-4.

31. Koerber, J. T.; Thomsen, N. D.; Hannigan, B. T.; Degrado, W. F.; Wells, J. A., Natureinspired design of motif-specific antibody scaffolds. Nature Biotechnology 2013, 31 (10), 916921.

32. Kwon, H.-K.; Bae, G.-U.; Yoon, J.-W.; Kim, Y. K.; Lee, H.-Y.; Lee, H.-W.; Han, J.-W., Constitutive activation of p70S6k in cancer cells. Arch. Pharm. Res. 2002, 25 (5), 685-690.

33. Srinivasan, D.; Plattner, R., Activation of Abl tyrosine kinases promotes invasion of aggressive breast cancer cells. Cancer Res 2006, 66 (11), 5648-55.

34. Salh, B.; Marotta, A.; Matthewson, C.; Ahluwalia, M.; Flint, J.; Owen, D.; Pelech, S., Investigation of the Mek-MAP kinase-Rsk pathway in human breast cancer. Anticancer research 1999, 19 (1b), 731-40.

35. Gharbi, S. I.; Zvelebil, M. J.; Shuttleworth, S. J.; Hancox, T.; Saghir, N.; Timms, J. F.; Waterfield, M. D., Exploring the specificity of the PI3K family inhibitor LY294002. Biochem J 2007, 404 (1), 15-21.

36. Horwell, D. C.; Howson, W.; Naylor, D.; Osborne, S.; Pinnock, R. D.; Ratcliffe, G. S.; Suman-Chauhan, N., Alanine scan and N-methyl amide derivatives of Ac-bombesin[7-14]. Development of a proposed binding conformation at the neuromedin B (NMB) and gastrin releasing peptide (GRP) receptors. International journal of peptide and protein research 1996, 48 (6), 522-31.

37. Cardó-Vila, M.; Giordano, R. J.; Sidman, R. L.; Bronk, L. F.; Fan, Z.; Mendelsohn, J.; Arap, W.; Pasqualini, R., From combinatorial peptide selection to drug prototype (II): targeting the epidermal growth factor receptor pathway. Proceedings of the National Academy of Sciences of the United States of America 2010, 107 (11), 5118-5123.

38. Wallbrecher, R.; Ackels, T.; Olea, R. A.; Klein, M. J.; Caillon, L.; Schiller, J.; Bovee-Geurts, P. H.; van Kuppevelt, T. H.; Ulrich, A. S.; Spehr, M.; Adjobo-Hermans, M. J. W.; Brock, R., Membrane permeation of arginine-rich cell-penetrating peptides independent of transmembrane potential as a function of lipid composition and membrane fluidity. $J$ Control Release 2017, 256, 68-78.

39. Barducci, A.; Bussi, G.; Parrinello, M., Well-Tempered Metadynamics: A Smoothly Converging and Tunable Free-Energy Method. Physical Review Letters 2008, 100 (2), 020603. 40. Trinh, T. B.; Upadhyaya, P.; Qian, Z.; Pei, D., Discovery of a Direct Ras Inhibitor by Screening a Combinatorial Library of Cell-Permeable Bicyclic Peptides. ACS Combinatorial Science 2016, 18 (1), 75-85.

41. Gógl, G.; Kornev, A. P.; Reményi, A.; Taylor, S. S., Disordered Protein Kinase Regions in Regulation of Kinase Domain Cores. Trends Biochem Sci 2019, 44 (4), 300-311.

42. Rezai, T.; Bock, J. E.; Zhou, M. V.; Kalyanaraman, C.; Lokey, R. S.; Jacobson, M. P., Conformational Flexibility, Internal Hydrogen Bonding, and Passive Membrane Permeability: Successful in Silico Prediction of the Relative Permeabilities of Cyclic Peptides. Journal of the American Chemical Society 2006, 128 (43), 14073-14080. 
